\title{
Stability of Soil Cutting and Side Slope Based on Stress Route Theory
}

\author{
Zhaohong Ji* \\ Jiangsu Traffic Science Research Institute Co., Ltd., Nanjing, Jiangsu 210000, China
}

ABSTRACT The stress route analytical method compensates for the limitation of traditional soil slope stability analytical method. Since it disregards the impact of effective stress route on the stress status and anti-shear strength of soil slope, it maps out the soil stress route drawing in the excavation process, and marks the anti-shear strength and shear stress changes under various conditions of soil. It causes the changes of the safety coefficient rules in the excavation of soil slope and affects the excavation stability of soil cutting and side slope. The result reveals: (1) The main analytical method of side slope stability which covers both the limit balance method and finite unit method fails to consider the impact of effective stress route on the existing stress status and anti-shear strength of soil slope; the stress route analytical method is able to overcome this limitation to a certain degree. (2) The stress route theory is adopted for analysis, in which, it can projected the whole stress of typical and most dangerous area of the slope, able to analyse the anti-shear strength of soil in a real-time manner, manage to express the safety coefficient changes in the stress route drawing and provides a selection of a suitable excavation plan by contrast. (3) In the overall excavation, the slope toe suffers from obvious stress concentration which expands to the surrounding areas and inconvenient for the side slope stability in the excavation.

\section{KEYWORDS}

Stress route

Stability of soil slope

Anti-shear strength

Safety coefficient

\section{Introduction}

Currently, the following stability analytical methods of soil cutting and side slope are adopted frequently: limit balance analytical method and finite unit method $[1,2]$, in which, both of the methods have the following defects: (1) In the analysis of complete damage against soil slope, c and $\varphi$ of the soil refer to parameters upon complete damage. Therefore, safety coefficient upon complete damage against soil slope is provided. If the strain is adopted as the damage principle of soil slope, the similar test is made to obtain $\mathrm{c}$ and $\varphi$ of a certain strain-in actual fact, it suffers from certain problems. The limit balance analysis breaches against the assumption of limit balance status. Therefore,

Copyright ( 2015 Zhaohong Ji

doi: $10.18686 /$ utc.v2i1.1

Received: October 3, 2015; Accepted: October 26, 2015; Published online: December 4, 2015

This is an open-access article distributed under the terms of the Creative Commons Attribution Unported License (http://creativecommons.org/ licenses/by-nc/4.0/), which permits unrestricted use, distribution, and reproduction in any medium, provided the original work is properly cited.

${ }^{*}$ Corresponding author: Jiangsu Traffic Science Research Institute Co., Ltd., Nanjing, Jiangsu 210000, China. E-mail: jizhaohong123@sina.com we will only consider the static balance of each soil strip to calculate the delicate dynamic surface whereby the slide force is unreasonable. (2) The positive stress is the existing value of damaged surface. The resistance slide force is true only when soil slope remains unchanged from the existing stress status to the damaged status. If the positive stress shows an increasing trend, the safety coefficient of soil slope is rather conservative. (3) As is known to all, the soil stress-strain relationship and anti-shear strength are affected by the effective stress route. In the analysis of limit balance and finite element methods, it fails to consider the impact of effective stress route on the existing stress status and anti-shear strength of soil slope.

Based on the defects of limit balance method and finite unit method, Gao and Zhang (1997) [3] elaborates on even suitable analytical methods to the soil slope stability: (1) The damage principle adopted to calculate the anti-skid resistance of soil slope considering the impact of previous and future stress route of soil slope; it remains valid under a certain strain level; (2) The impact of soil slope lossof-stability on the effective stress route is considered; the existing stress status of soil slope is calculated; (3) Suitable and convenient soil structure model is adopted. Therefore, 
the soil slope stability analytical method is introduced.

The said calculation methods of soil slope stability have rather complex procedures. If the finite unit method or limit differential method is adopted, may provide a convenient analytical method. Therefore, this article aims to analyse the changing trend of stress route in different positions of soil slope under different excavation methods, to estimate possible stress route of soil with accordance to the said calculation methods of soil slope stability, to integrate with the limit differential method for the simulation analysis of the side slope excavation, and ultimately, to analyse the soil slope stability.

\section{Analysis of stress route and safety coefficient in the excavation of soil cutting}

The soil cutting project will release the horizontal and vertical stress in the construction and excavation of retaining soil structure. The stress depends on the initial stress, construction methods and cutting excavation depth.

Upon excavation of soil in the side slope, the side slope exists as a separate soil unit; the original mechanical balance of the soil is damaged; it is a stress release process from initial stress conditions of soil to soil stress status of side slope project; the mechanical stress is mainly demonstrated in the load discharge features [4-6].

If the cutting is excavated in the section direction for a long range and soil is assumed to have the same nature in the same direction, the stress change of soil unit is assumed to be a plane strain status. At the same time, the cutting soil is assumed to maintain a natural stress status in the initial stage: $k_{0}$ solidified status. Under such assumptions, the stress route is analysed in the excavation of slope surface, slope toe and bottom of cutting and side slope project:

$$
\begin{aligned}
& p=\left(\sigma_{1}+\sigma_{3}\right) / 2 \\
& q=\left(\sigma_{1}-\sigma_{3}\right) / 2
\end{aligned}
$$

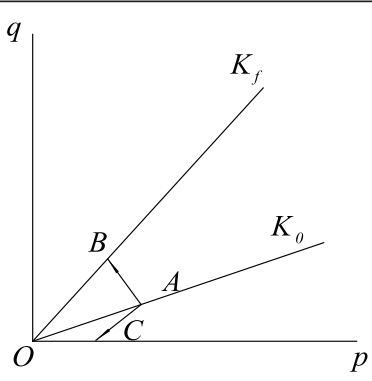

Figure 1. Sketch map on the stress path of slope excavation.

(1) Excavation slope surface: Under its own gravity and stress, the soil has basically completed the water discharge and solidification. With the excavation of side slope, the slope surface has lateral displacement and horizontal stress is reduced gradually. This process is known as lateral load discharge whereby the vertical gravity and stress remain basically unchanged whereas the horizontal stress is in be- tween of static soil pressure and active soil pressure. With increased excavation depth, the horizontal displacement of slope surface is constantly increased, hence allowing the horizontal stress developed from $k_{0}$ status to limit status of active soil pressure. Please refer to $A B$ in Figure 1 for details.

(2) Bottom of side slope: Upon excavation of upper part of subgrade soil beneath the bottom of side slope, the upper coverage pressure, vertical gravity and stress are reduced which is known as axial load discharge. With bulging of slope bottom and inward displacement of support and protective structure, the horizontal stress may be increased or reduced. Generally, the soil unit is assumed as follows: horizontal stress remains unchanged and vertical stress is reduced. Please refer to AC in Figure 1 for the stress route in detail.

(3) Side slop toe (boundary between slope surface and toe): Since it is located in the boundary between slope surface and toe with a given particular position, the mechanical property is between the surface and bottom of the slope. In the excavation, the vertical stress and horizontal stress are reduced at the same time and stress route is between $\mathrm{AB}$ and $\mathrm{AC}$. It may be located above or under $k_{0}$ line in proportionate to the specific excavation process. The stress concentration is easily discovered rather than slope surface and bottom; therefore, it is often used as the analytical object.

\section{Analysis of project application cases 3.1. Project overview}

This article selects main typical side slope as the basis of the study. It is located along the make-up section of main highway of Erhe National Highway; the Yunnan Zhaotong-Make-up Highway with $180 \mathrm{~m}$ soil side slope of $(\mathrm{K} 336+520) \sim(\mathrm{K} 336+700)$ section were adopted as the subject of the research. The outdoor investigation reveals that oil side slope is the main category of make-up section highway. In order to explore the stability mechanism of typical side slope and provide a reliable basis for governance design, the deformation mechanism of soil side slope must be taken into consideration. The side slope is located in the black soil layer; the internal typography is featured as erosive structural landform and partial valley accumulation landform; the karst landform is highly developed. The stratum is featured as red brown, brown red, yellow mild clay and red clay in the upper part; the layer thickness is $2-10 \mathrm{~m}$ in general; the black soil layer is $38.1 \mathrm{~m}$ in thickness. The thickness has large changes [4].

\subsection{Model establishment and parameter setup}

In order to simulate the deformation damage mechanism of soil side slope, the model is established according to the documents from the geological investigation of side slope in a certain expressway section in order to reflect the gen- 
eral features. As for natural side slope, three excavation plans are adopted in the sections of different elevations to simulate the excavation:

Plan 1: Overall excavation: According to the designed gradient of 1:1, excavation in five layers on average will generate a general excavation depth of $20 \mathrm{~m}$;

Plan 2: Step excavation: Excavation comes in two steps: The $1^{\text {st }}$ level step has a designed gradient of 1:1 with excavation depth of $10 \mathrm{~m}$, in which, it will be excavated in two layers according to the depth. The $2^{\text {nd }}$ level step has a designed gradient of 1:1 with excavation depth of $10 \mathrm{~m}$, and will be excavated in two layers according to the depth. Please refer to Table 1 for the calculation parameters of model.

FLAC 5.00 software is used to simulate the side slope value under different excavation methods. In view of model establishment complexity, the side slope is simply settled in the model establishment of side slope. The slope weight effect is considered in the analysis while the structural stress field is neglected. Besides that, the historical stress of soil, initial displacement field and stress field of soil caused by side slope excavation were also ignored. As a matter of fact, the soil is deemed as an elastic-plastic material. Duncan-Chang structural model was used as the reference model using the Morh-Columb principle; which is automatically distributed according to FLAC 5.0 software. The bottom boundary of model is collocated with X, Y two-way restriction while surrounding boundary is collocated with $\mathrm{X}$ one-way restriction. Each model has two curves: the upper curve is a folded line which means the excavation line; the lower curve is an underground water level line.

Table 1. Model calculation parameter.

\begin{tabular}{lccccc}
\hline $\begin{array}{c}\text { Calculation } \\
\text { parameters }\end{array}$ & $\gamma\left(\mathrm{KN} / \mathrm{m}^{3}\right)$ & $\mathrm{C}(\mathrm{KPa})$ & $\varphi\left({ }^{\circ}\right)$ & $\mu$ & $E_{0}(\mathrm{MPa})$ \\
\hline Above water level & 1900 & 45 & 30 & 0.3 & 8.5 \\
Below water level & 1800 & 40 & 25 & 0.3 & 8.5 \\
\hline
\end{tabular}

\subsection{Calculation result and analysis}

In order to simulate the construction in the table of calculation, the load is excavated and released level by level. The stress route in the bottom layer of slope toe is adopted as the investigation object.

\subsubsection{Result and analysis of overall excavation}

In the calculation of excavation, the first effective main stress and third effective main stress in each layer of excavation section in the slope toe (boundary between slope surface and bottom) are shown in Table 2 .

Table 2. Principal stress data (unit: $10^{5} \mathrm{~Pa}$ ).

\begin{tabular}{llllll}
$\sigma_{1}^{\prime}$ & 2.61 & 2.47 & 2.44 & 2.43 & 2.37 \\
\hline$\sigma_{3}^{\prime}$ & 1.69 & 1.33 & 1.20 & 1.07 & 0.89 \\
\hline
\end{tabular}

According to the formula: $p^{\prime}=\frac{\sigma_{1}^{\prime}+\sigma_{3}^{\prime}}{2}, q=\frac{\sigma_{1}^{\prime}-\sigma_{3}^{\prime}}{2}$, the maximum effective positive stress $p^{\prime}$ and effective shear stress $q^{\prime}$ are shown in Table 3 .

Table 3. Most effective pressure $p^{\prime}$ and shear stress $q^{\prime}$ (unit: $\left.10^{5} \mathrm{~Pa}\right)$.

\begin{tabular}{llllll}
\hline$p^{\prime}$ & 2.15 & 1.90 & 1.82 & 1.75 & 1.63 \\
\hline$q^{\prime}$ & 0.46 & 0.57 & 0.62 & 0.68 & 0.74 \\
\hline
\end{tabular}

According to the relationship between anti-shear strength line $k_{f}$ 's inclination angle $\alpha$ and inner friction angle $\varphi$, it is found that $\alpha=\arctan (\sin \varphi)=27^{\circ}$. Then the formula was integrated with $p^{\prime}$ and $q^{\prime}$ in the Table 3 and obtained the data in Figure 2.

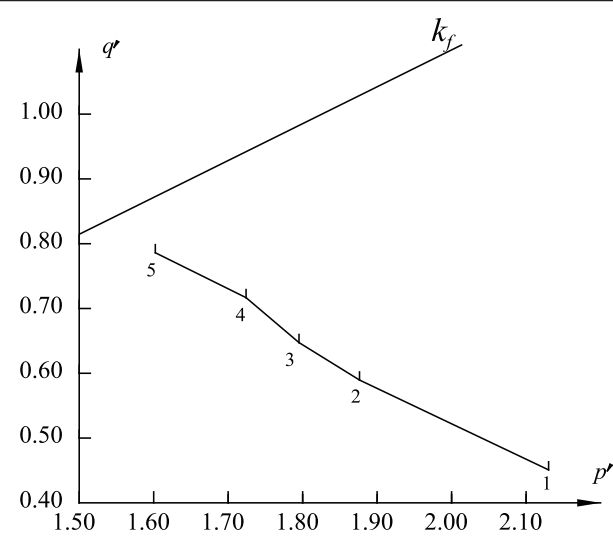

Figure 2. Excavation stress path of toe of slope on the $1^{\text {st }}$ project.

It can be concluded that the maximum effective positive stress $p^{\prime}$ is constantly reduced while effective shear stress $q^{\prime}$ is gradually increased. Ultimately, the result is near to the anti-shear strength line with the stress route of slope toe soil shows reduction in $p^{\prime}$ features and the corresponding anti-shear strength prevailed unchanged. The corresponding safety coefficients to various points are as follows:

$$
\begin{aligned}
& F_{1}=0.83 / 0.45=1.85 \\
& F_{2}=0.83 / 0.59=1.41 \\
& F_{3}=0.83 / 0.65=1.28 \\
& F_{4}=0.83 / 0.72=1.15 \\
& F_{5}=0.83 / 0.79=1.05
\end{aligned}
$$

Therefore, the safety coefficient is constantly reduced (near 1) which is technically unfavourable to the excavation.

\subsubsection{Result and analysis of step excavation}

In the calculation of excavation, $2^{\text {nd }}$ level step slope toe (boundary between slope surface and bottom) is adopted and two layers of completed sections $\left(1^{\text {st }}\right.$ level and $2^{\text {nd }}$ level $)$ are excavated; in four sections, $1^{\text {st }}$ effective main stress $\sigma_{1}^{\prime}$ and $3^{\text {rd }}$ effective main stress $\sigma_{3}^{\prime}$ are shown in Table 4. The 
first two groups of data refer to the stress of $1^{\text {st }}$ excavation layer; the last two groups of data refer to the stress of $2^{\text {nd }}$ excavation layer.

Table 4. Principal stress data (unit: $10^{5} \mathrm{~Pa}$ ).

\begin{tabular}{lllll}
\hline$\sigma_{1}^{\prime}$ & 2.69 & 2.50 & 2.31 & 2.11 \\
\hline$\sigma_{3}^{\prime}$ & 1.87 & 1.82 & 1.65 & 1.59 \\
\hline
\end{tabular}

According to the formula: $p^{\prime}=\frac{\sigma_{1}^{\prime}+\sigma_{3}^{\prime}}{2}, q=\frac{\sigma_{1}^{\prime}-\sigma_{3}^{\prime}}{2}$, the maximum effective positive stress $p^{\prime}$ and effective shear stress $q^{\prime}$ are shown in Table 5.

Table 5. Most effective pressure $p^{\prime}$ and shear stress $q^{\prime}$ (unit: $\left.10^{5} \mathrm{~Pa}\right)$.

\begin{tabular}{lllll}
\hline$p^{\prime}$ & 2.27 & 2.16 & 1.98 & 1.85 \\
\hline$q^{\prime}$ & 0.53 & 0.47 & 0.45 & 0.26 \\
\hline
\end{tabular}

According to the relationship between anti-shear strength line $k_{f}$ 's inclination angle $\alpha$ and inner friction angle $\varphi$, it is found that $\alpha=\arctan (\sin \varphi)=27^{\circ}$. Then the formula was integrated with $p^{\prime}$ and $q^{\prime}$ in the table and obtain the data in Figure 3.

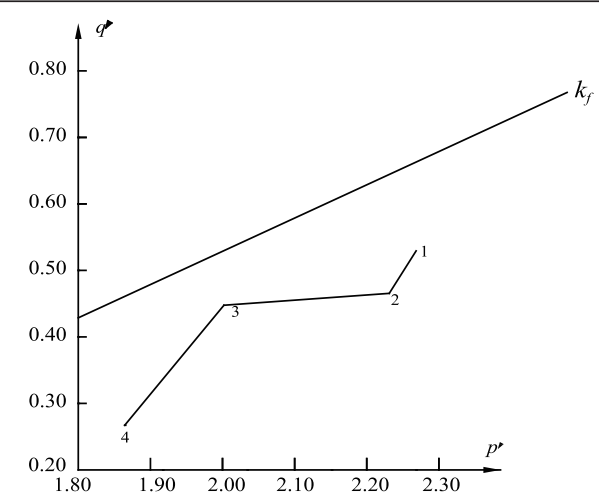

Figure 3. Excavation stress path of toe of slope on the $2^{\text {nd }}$ project.

From the result, it can be concluded that the maximum effective positive stress $p^{\prime}$ is constantly reduced while effective shear stress $q^{\prime}$ is gradually reduced. In the whole excavation, the stress route line departs from the anti-shear strength line $k_{f}$. The corresponding safety coefficients to various points are as follows:

$$
\begin{aligned}
& F_{1}=0.78 / 0.53=1.48 \\
& F_{2}=0.78 / 0.47=1.66 \\
& F_{3}=0.58 / 0.45=1.28 \\
& F_{4}=0.58 / 0.26=2.23
\end{aligned}
$$

Therefore, the soil safety coefficient is constantly increased which is favourable to the excavation safety and smoothness; this excavation plan can be adopted properly.

\section{Conclusion}

This article is aims at the traditional analytical method of side slope stability and disregard the impact of stress route on soil stress-strain relationship and anti-shear strength. Therefore, the stress route theory was proposed by analysing the stability of soil slope and the stress route of various slope in the excavation of soil cutting and side slope area. On top of that, the safety coefficient changes of slope toe soil under different excavation methods was also observed and launched out case verification. As a result, a systematic approach with regards to the stability of soil side slope was constructed and draws the following conclusions:

(1) Currently, the main analytical methods of side slope stability which includes both the limit balance method and finite unit method fail to consider the impact of effective stress route on existing soil slope's stress status and antishear strength. However, the stress route analytical method is able to overcome the shortcomings to a certain degree.

(2) The proposed stress route theory successfully records the whole stress of typical and most dangerous area of the slope, able to analyse the anti-shear strength of soil in a real-time manner, manage to express the safety coefficient change in the stress route drawing and provides a suitable selection of excavation plan by contrast.

(3) The slope toe suffers from obvious stress concentration, in which, it is expanded to the surrounding areas and inconvenient for the side slope stability in the excavation plan.

(4) In comparison to the overall excavation plan, the excavation step attenuates the stress concentration in the slope toe and unable to estimate the slope stability.

(5) From the perspective of stress route, the shear stress of slope toe is constantly increased while anti-shear strength is gradually reduced. Therefore, the safety coefficient is constantly reduced which indirectly affects the slope stability.

(6) In the excavation step, the soil safety coefficient is constantly increased and the slope shows a favourable stability. The proposed stress route theory can be implemented for the excavation plan as it covers both straightforward and scientific methodologies.

\section{References}

1. Li, H. (2003). Research on Deformation and Stability of Residual Soil Side Slope of Cutting Type Slope. Fuzhou, Fuzhou University.

2. Xu, Y. H. (2005). Research on Stability of Soil Cutting Side Slope. Kunming, Kunming University of Technology.

3. Gao, Z. Z., \& Zhang, Q. Y. (1997). Stability Analytic Methods of Soil Slope Based on Stress Route Impact. Journal of Southwest Jiaotong University, 32(4), 370-376.

4. He, S. X., Yu, Y. X., \& Wu, G. G. (2004). Test Research into Impact of Stress Route on Anti-shear Strength Indicators. Journal of Hubei Institute of Technology, 19(1),1-5.

5. Wang, G. T., Yi, Z. H., \& Hu, Z. Z. (2004). Simulation of Finite Elements of Stress Re-nurturing Methods in Side Slope Excavation. Journal of Hefei University of Technology (Natural Science Version), 27(4), 368-371.

6. Liang, B., \& Sun, Y. Q. (2000). Higher Mechanical Property of Soil. Lanzhou. 